International Journal of Pure and Applied Mathematics

Volume 103 No. 3 2015, 485-497

ISSN: 1311-8080 (printed version); ISSN: 1314-3395 (on-line version)

url: http://www.ijpam.eu

doi: http://dx.doi.org/10.12732/ijpam.v103i3.10

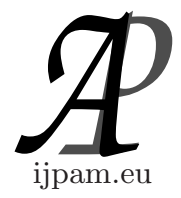

\title{
GLOBAL OPTIMIZATION APPROACH TO UTILITY MAXIMIZATION PROBLEM
}

\author{
R. Enkhbat ${ }^{1}$, J. Enkhbayar ${ }^{2}$, A. Griewank ${ }^{3}$ \\ ${ }^{1}$ The School of Business \\ National University of Mongolia \\ P.O. Box 46/635, Ulaanbaatar, 210646, MONGOLIA \\ ${ }^{2}$ School of Engeenering and Aplied Science \\ National University of Mongolia \\ ${ }^{3}$ Humboldt University Berlin \\ GERMANY
}

\begin{abstract}
We consider the utility maximization problem for oligopsonistic market which is nonconvex optimization problem. Unlike the utility maximization for competitive market, the problem belongs to a class of global optimization. The purpose of this paper is to develop a theory and method for the above problem. We derive a new global optimality condition for our problem and based on this we propose a method which converges globally. Some test problems are examined.
\end{abstract}

AMS Subject Classification: 49K30, 90C90, 90C26, 91B42

Key Words: utility maximization problem, global optimality condition, oligopsonistic market, algorithm

\section{Introduction}

The theory of mathematical programming has been applied to a wide variety of problems in economics. It has been used to characterize the solution of fundamental problems in virtually all areas of economics. Microeconomic problems are typically formulated as those of economic agents (consumers and firms) at-

Received: May 4, 2015

(c) 2015 Academic Publications, Ltd.

$\S_{\text {Correspondence author }}$ url: www.acadpubl.eu 
tempting to maximize an objective function subject to certain constrains. The utility maximization as a part of general equilibrium and nonconvex analysis [1], [8] plays an important role in economics and optimization theory. There are number of works [5], [7], [10], [14], [11], [13], [15] devoted to the utility maximization for competitive market but it seems that less attention has been paid so far to theory and methods for utility maximization in oligopsonistic market. Usually, the utility maximization problem for competitive market is formulated as (see [15]):

$$
U(x) \rightarrow \max , x \in D,
$$

subject to:

$$
D=\left\{x \in \mathbb{R}^{n} \mid \sum_{i=1}^{n} p_{i} x_{i}=m, x_{i} \geq 0, i=1, \ldots, n\right\},
$$

where $x=\left(x_{1}, x_{2}, \ldots, x_{n}\right)$ is a vector of basket of produced goods $(i=1, \ldots, s)$ and resources $(j=s+1, \ldots, n)$ to be consumed and supplied by a consumer, $U: \mathbb{R}_{+}^{n} \rightarrow \mathbb{R}$ is the utility function representing the preference of an individual, $p=\left(p_{1}, p_{2}, \ldots, p_{n}\right)$ is a vector of market prices of goods and resources, and $m$ is the individual income.

In 1 the consumer chooses a basket maximizing his utility function over budget constrained set $\mathrm{D}$. The utility function $U(x)$ is always concave due to the marginal utility diminishing law [15], and typically assumed to be differentiable over $\mathrm{D}$, and variables $x_{j}$ are continuous, representing divisible and continuous goods in the perfect competitive market. In this context, problem 1 is referred to as the classical model of utility maximization [6], [7], [8], [11], [13]. The utility maximization problem plays a key role in the consumer theory which is an important part of the general equilibrium in economics. Solution $x_{j}=$ $x_{j}(p, m), j=1, \ldots s$ give demands for goods of a consumer, and solutions $x_{j}=$ $x_{j}(p, m), \quad j=s+1 \ldots, m$ constitute supplies of a resources by a consumer for firms. The sum of all such demands and supplies over all consumer constitutes a market demand and supply from the consumer side.

The paper is organized as follows. In Section 2, we consider the utility maximization in oligopsonistic market. Section 3 has been devoted to a method and algorithm for solving the problem. Numerical results are given in Section 4 .

\section{Nonconvex Utility Maximization Problem}

Sometime nonconvexities arise in the utility maximization under certain noncompetitive market, the consumer influences the market price through the 
amount that he purchases. Thus, if the market for good $\{i\}$ is oligopsonistic in this way, then $p_{i}$ is a function of $x_{i}$, i.e, $p_{i}=p_{i}\left(x_{i}\right)$. If markets for all goods are oligopsonistic, then the utility maximization problem is:

$$
\begin{aligned}
& f(x) \longrightarrow \max , x \in D, \\
& D=\left\{x \in \mathbb{R}^{n} \mid \sum_{i=1}^{n} p_{i}\left(x_{i}\right) x_{i}=m, x_{i} \geq 0, \quad i=1, \ldots, n\right\}
\end{aligned}
$$

where $f: \mathbb{R}_{+}^{n} \longrightarrow \mathbb{R}$ is strongly concave and continuously differentiable, $p_{i}$ : $\mathbb{R}_{+}^{n} \longrightarrow R,(i=1, \ldots, n)$ are continuous and $D$ is a compact set in $\mathbb{R}_{+}^{n}$.

Problem (2) is nonconvex due to the nonconvex constraint $D$. In general, there is no efficient algorithm for solving this problem globally. However, under certain assumption, we can prove the optimality conditions for problem (2), and then develop an algorithm based on this.

Denote by $x^{*}$ the unique global maximizer of $f$ on $\mathbb{R}^{n}$ which exists due to the strong convexity [4], that is:

$$
f\left(x^{*}\right)=\max _{x \in \mathbb{R}^{n}} f(x) .
$$

Define the set $E_{c}(f)$ :

$$
E_{c}(f)=\left\{y \in \mathbb{R}^{n} \mid f(y)=c\right\} .
$$

Theorem 2.1. If $x^{*} \notin D$ then $z \in D$ is a global maximizer of problem (2) if and only if

$$
\left\langle f^{\prime}(x), x-y\right\rangle \leq 0
$$

for all $y \in E_{f(z)}(f)$ and $x \in D$. If, in addition,

$$
\min _{x \in D}\left\|f^{\prime}(x)\right\|>0
$$

then condition (3) is sufficient for $z$ to be global.

Proof. Necessity. Assume that $z$ is a solution of problem (2). Consider $x \in D$ and $y \in E_{f(z)}(f)$. Then by the concavity of $f$, we have

$$
0<f(z)-f(x)=f(y)-f(x) \leq\left\langle f^{\prime}(x), y-x\right\rangle .
$$

Sufficiency. Let us prove the assertion by contradiction. Assume that (3) holds and exists a point $u \in D$ such that

$$
f(u)>f(z) .
$$


Clearly, $f^{\prime}(u) \neq 0$ by the assumption of the Theorem. Now define $u_{\alpha}$ for $\alpha>0$ as follows:

$$
u_{\alpha}=u-\alpha f^{\prime}(u) .
$$

Then, by the concavity of $f$, we have

$$
f\left(u_{\alpha}\right)-f(u) \leq\left\langle f^{\prime}(u), u_{\alpha}-u\right\rangle=-\alpha\left\|f^{\prime}(u)\right\|^{2},
$$

which implies

$$
f\left(u_{\alpha}\right) \leq f(u)-\alpha\left\|f^{\prime}(u)\right\|^{2}<f(u) .
$$

Then find $\alpha=\bar{\alpha}$ such that

$$
f(u)-\alpha\left\|f^{\prime}(u)\right\|^{2}=f(z),
$$

that is,

$$
\bar{\alpha}=\frac{f(u)-f(z)}{\left\|f^{\prime}(u)\right\|^{2}}>0 .
$$

Thus, we get

$$
f\left(u_{\alpha}\right) \leq f(u)-\bar{\alpha}\left\|f^{\prime}(u)\right\|^{2}=f(z)<f(u) .
$$

Define a function $h: \mathbb{R}^{+} \rightarrow \mathbb{R}$ as

$$
h(\alpha)=f\left(u-\alpha f^{\prime}(u)\right)-f(z),
$$

where $\mathbb{R}^{+}=\{\alpha \in \mathbb{R} \mid \alpha \geq 0\}$. It is clear that $h$ is continuous on $[0,+\infty)$. Note that $h(\bar{\alpha}) \leq 0$ and $h(0)>0$. There are two cases with respect to the value of $h(\bar{\alpha})$ which we should consider.

Case 1. $h(\bar{\alpha})=0$, then

$$
\left\langle f^{\prime}(u), u-u_{\bar{\alpha}}\right\rangle=\left\langle f^{\prime}(u), \bar{\alpha} f^{\prime}(u)\right\rangle=\bar{\alpha}\left\|f^{\prime}(u)\right\|^{2}>0
$$

contradicting condition (3).

Case 2. $h(\bar{\alpha})<0$ and $h(0)>0$. Since $h$ is continuous, there exists a point $\alpha_{0} \in(0, \bar{\alpha})$ such that $h\left(\alpha_{0}\right)=0$ (or $f\left(u+\alpha_{0} f^{\prime}(u)\right)=f(z)$.) Then we have

$$
\left\langle f^{\prime}(u), u-u_{\alpha_{0}}\right\rangle=\alpha_{0}\left\|f^{\prime}(u)\right\|^{2}>0
$$

again contradicting condition (3).

Thus, in both cases, we find contradictions, proving the theorem.

Remark 1. Theorem 2.1 states that, in order to conclude that a point $z \in D$ is not a solution of (2) it is sufficient to have a pair $(v, y) \in \mathbb{R}^{n}$ such that 


$$
\left\langle f^{\prime}(v), v-y\right\rangle>0, y \in E_{f(z)}(f) \text { and } v \in D \text {. }
$$

Remark 2. Under certain assumptions, global optimality conditions similar to condition (3) was obtained in [9] for the quasiconvex case.

Before we describe an algorithm for (2), we define the function $g(y)$ an $\psi(z)$ as follows:

$$
\begin{gathered}
g(y)=\max _{x \in D}\left\langle f^{\prime}(x), x-y\right\rangle, y \in \mathbb{R}^{n}, \\
\psi(z)=\max _{y \in E_{f(z)}(f)} g(y), z \in D .
\end{gathered}
$$

Now we can reformulate Theorem 2.1 in the following.

Theorem 2.2. Assume that $f: \mathbb{R}_{+}^{n} \longrightarrow R$ is strongly concave and continuously differentiable. Let $D$ be a compact set in $\mathbb{R}_{+}^{n}$, and $x^{*} \notin D$. If $\psi(z)=0$ then a point $z$ is a global maximizer of problem (2).

Proof. This is an obvious consequence of the following relations.

$$
0=\psi(z) \geq g(y) \geq\left\langle f^{\prime}(x), x-y\right\rangle,
$$

which are fulfilled for all $y \in E_{f(z)}(f)$ and $x \in D$. The proof is complete.

Now we are ready to present an algorithm for solving problem (2). We also suppose that one can efficiently solve the problem of computing $\max _{x \in D}\left\langle f^{\prime}(x), x-\right.$ $y\rangle$ for any given $y \in \mathbb{R}^{n}$.

\section{Algorithm NUMP}

Step 1. Choose a feasible point $x^{0} \in D$. Set $\mathrm{k}:=0$.

Step 2. Solve the following problem

$$
g(y) \longrightarrow \max , y \in E_{f\left(x^{k}\right)}(f) .
$$

Let $y^{k}$ be a solution to this problem, i.e.

$$
g\left(y^{k}\right)=\max _{x \in D}\left\langle f^{\prime}(x), x-y^{k}\right\rangle=\max _{y \in E_{f\left(x^{k}\right)}(f)} g(y),
$$

and let $x^{k+1}$ realizes $g\left(y^{k}\right)$ :

$$
\psi\left(x^{k}\right)=\left\langle f^{\prime}\left(x^{k+1}\right), x^{k+1}-y^{k}\right\rangle .
$$


Step 3. If $\psi\left(x^{k}\right)=0$ the output $x^{* *}:=x^{k}$ and terminate. Otherwise, let $k:=k+1$ and return to step 2 .

The convergence of this algorithm is based on the following theorem.

Theorem 3.1. The sequence $\left\{x^{k}, k=0,1, \ldots,\right\}$ generated by Algorithm NUMP is a maximizing sequence for problem (2), that is,

$$
\lim _{k \longrightarrow \infty} f\left(x^{k}\right)=\max _{x \in D} f(x),
$$

and an accumulation of the sequence $\left\{x^{k}\right\}$ is a global maximizer of (2).

Proof. From the construction of the sequence $\left\{x^{k}\right\}$, we have $x^{k} \in D$ and $f^{*} \geq f\left(x^{k}\right)$ for all $k$, where $f^{*}=f\left(x^{* *}\right)=\max _{x \in D} f(x)$. Clearly, $f^{\prime}\left(x^{* *}\right) \neq 0$ by assumption. Also, note that for all $y \in E_{f(z)}(f)$ and $x \in D$, we have

$$
\psi\left(x^{k}\right)=\max _{y \in E_{f\left(x^{k}\right)}(f)} \max _{x \in D}\left\langle f^{\prime}(x), x-y\right\rangle \geq\left\langle f^{\prime}(x), x-y\right\rangle .
$$

In particular,

$$
\psi\left(x^{k}\right) \geq 0 .
$$

If there exists a $k$ such that $\psi\left(x^{k}\right)=0$ then, by Theorem $2.2, x^{k}$ is a solution to problem (3) and, in this case the proof is complete. Therefore, without loss of generality, we can assume $\psi\left(x^{k}\right)>0$ for all $k$, and prove the theorem by contradiction. If the assertion is false, that is, $\left\{x^{k}\right\}$ is not a maximizing sequence for problem (2), the following inequality holds.

$$
\lim _{k \rightarrow \infty} \sup f\left(x^{k}\right)<f^{*}
$$

By the definition of $\psi\left(x^{k}\right)$ and Algorithm NUMP, we have

$$
g\left(y^{k}\right)=\psi\left(x^{k}\right)=\max _{y \in E_{f\left(x^{k}\right)}(f)} \max _{x \in D}\left\langle f^{\prime}(x), x-y\right\rangle=\left\langle f^{\prime}\left(x^{k+1}\right), x^{k+1}-y^{k}\right\rangle
$$

and $f\left(x^{k}\right)=f\left(y^{k}\right)$. The concavity of $f$ implies that

$$
\begin{aligned}
& f\left(x^{k}\right)-f\left(x^{k+1}\right)=f\left(y^{k}\right)-f\left(x^{k+1}\right) \leq \\
& \left\langle f^{\prime}\left(x^{k+1}\right), y^{k}-x^{k+1}\right\rangle=-\psi\left(x^{k}\right)<0
\end{aligned}
$$

Hence, we obtain $f\left(x^{k}\right)<f\left(x^{k+1}\right)$ for all $k$, and the sequence $\left\{f\left(x^{k}\right)\right\}$ is strictly increasing. Since the sequence is bounded from above by $f^{*}$, it has a limit and satisfies 


$$
\lim _{k \rightarrow \infty}\left(f\left(x^{k}\right)-f\left(x^{k+1}\right)\right)=0
$$

Then, from (5) and (6), we obtain

$$
\lim _{k \rightarrow \infty} \psi\left(x^{k}\right)=0
$$

From (4) we have $f\left(x^{k}\right)<f^{*}$ for all $k$. Now define $v_{\alpha}$ as follows:

$$
v_{\alpha}=x^{* *}-\alpha f^{\prime}\left(x^{* *}\right), \alpha>0 .
$$

Then by the concavity of $f$, we have

$$
f\left(v_{\alpha}\right)-f\left(x^{* *}\right) \leq\left\langle f^{\prime}\left(x^{* *}\right), v_{\alpha}-x^{* *}\right\rangle=-\alpha\left\|f^{\prime}\left(x^{* *}\right)\right\|^{2},
$$

which implies

$$
f\left(v_{\alpha}\right) \leq f\left(x^{* *}\right)-\alpha\left\|f^{\prime}\left(x^{* *}\right)\right\|^{2}<f\left(x^{* *}\right), \alpha>0 .
$$

Choose $\alpha=\alpha_{k}$ such that

$$
f\left(x^{* *}\right)-\alpha_{k}\left\|f^{\prime}\left(x^{* *}\right)\right\|^{2}<f\left(x^{k}\right)
$$

that is,

$$
\alpha_{k}>\frac{f\left(x^{* *}\right)-f\left(x^{k}\right)}{\left\|f^{\prime}\left(x^{* *}\right)\right\|^{2}}>0 .
$$

Define a function $h_{k}: \mathbb{R}^{+} \rightarrow \mathbb{R}$ as

$$
h_{k}(\alpha)=f\left(x^{* *}-\alpha f^{\prime}\left(x^{* *}\right)\right)-f\left(x^{k}\right),
$$

where $\mathbb{R}^{+}=\{\alpha \in \mathbb{R} \mid \alpha \geq 0\}$. It is clear that $h_{k}$ is continuous on $[0,+\infty)$. Note that $h_{k}\left(\alpha_{k}\right) \leq 0$ and $h_{k}(0)>0$. Since $h_{k}$ is continuous, there exists a point $\overline{\alpha_{k}} \in\left(0, \alpha_{k}\right)$ such that $h_{k}\left(\overline{\alpha_{k}}\right)=0$, that is $f\left(v_{\overline{\alpha_{k}}}\right)=f\left(x^{k}\right)$ and $v_{\overline{\alpha_{k}}}=$ $x^{* *}-\overline{\alpha_{k}} f^{\prime}\left(x^{* *}\right)$. Also, note that

$$
\psi\left(x^{k}\right)=\max _{y \in E_{f\left(x^{k}\right)}(f)} \max _{x \in D}\left\langle f^{\prime}(x), x-y\right\rangle \geq\left\langle f^{\prime}\left(x^{* *}\right), x^{* *}-v_{\overline{\alpha_{k}}}\right\rangle .
$$

Taking into account $v_{\overline{\alpha_{k}}}=x^{* *}-\overline{\alpha_{k}} f^{\prime}\left(x^{* *}\right)$, we have

$$
-\psi\left(x^{k}\right) \leq\left\langle f^{\prime}\left(x^{* *}\right), v_{\overline{\alpha_{k}}}-x^{* *}\right\rangle \leq\left\|f^{\prime}\left(x^{* *}\right)\right\|\left\|v_{\overline{\alpha_{k}}}-x^{* *}\right\|=-\overline{\alpha_{k}}\left\|f^{\prime}\left(x^{* *}\right)\right\|^{2}<0 .
$$


Since $\lim _{k \rightarrow \infty} \psi\left(x^{k}\right)=0$, this implies

$$
\lim _{k \rightarrow \infty} v_{\bar{\alpha}_{k}}=x^{* *} .
$$

The continuity of $f$ on $\mathbb{R}^{n}$ yields

$$
\lim _{k \rightarrow \infty} f\left(x^{k}\right)=\lim _{k \rightarrow \infty} f\left(v_{\bar{\alpha}_{k}}\right)=f\left(x^{* *}\right) .
$$

which is contradiction to (4).

Consequently, $\left\{x^{k}\right\}$ is a maximizing sequence for problem (2). Since $D$ is compact, we can always select the convergent subsequences $\left\{x^{k_{l}}\right\}$ from $\left\{x^{k}\right\}$ such that

$$
\lim _{l \rightarrow \infty} x^{k_{l}}=\bar{x} \in D
$$

Then together with (7), we obtain

$$
\lim _{l \rightarrow \infty} f\left(x^{k_{l}}\right)=f(\bar{x})=f^{*},
$$

which completes the proof.

\section{Numerical Experiment}

In some case,computing $\psi\left(x^{k}\right)$, in Step 2 of Algorithm NUMP may not be easier than original problem. But if we can find a point $v \in D$ such that $\left\langle f^{\prime}(v), v-y^{k}\right\rangle>0$ during this computation, it implies $f(v)>f\left(x^{k}\right)$, improving the initial value of $f\left(x^{k}\right)$. Therefore, this $v$ may be used as $x^{k+1}$ in Step 2. A modification of Algorithm NUMP to incorporate this type of heuristic rule may turn out to be useful. Based on the above the following problems have been solved numerically.

$$
\begin{gathered}
f(x) \longrightarrow \max , x \in D \\
D=\left\{x \in \mathbb{R}^{n} \mid \sum_{i=1}^{n} p_{i}\left(x_{i}\right) x_{i}=m, x_{i} \geq 0, \quad i=1, \ldots, n\right\}
\end{gathered}
$$

Problem 1. Objective function:

$$
f(x)=-\left(x_{1}^{2}+x_{2}^{2}\right)
$$

Constraint functions:

$$
p_{1}\left(x_{1}\right)=\frac{1}{\ln ^{2} x_{1}+2}, \quad p_{2}\left(x_{2}\right)=\frac{1}{x^{\frac{3}{2}}+1}, m=1
$$


Solution: $x^{*}=\{1.0531 ; 0.9384\}$, Global value: $f^{*}=-1.9895$.

Problem 2. Objective function:

$$
f(x)=-\left(x_{1}^{2}+x_{2}^{2}\right)
$$

Constraint functions:

$$
p_{1}\left(x_{1}\right)=\frac{1}{x_{1}}, \quad p_{2}\left(x_{2}\right)=\frac{1}{x_{2}^{2}}, \quad m=10
$$

Solution: $x^{*}=\{0.2433 ; 0.4120\}$, Global value: $f^{*}=-0.2290$.

Problem 3. Objective function:

$$
f(x)=-\left(2 x_{1}^{2}+x_{2}^{2}+3 x_{3}^{2}+x_{4}^{2}\right)
$$

Constraint functions:

$$
\begin{gathered}
p_{1}\left(x_{1}\right)=\frac{1}{x_{1}^{2}+2}, \quad p_{2}\left(x_{2}\right)=\frac{1}{x_{2}^{2}+4 x_{2}+1}, \\
p_{3}\left(x_{3}\right)=\frac{1}{x_{3}^{2}+x_{3}+2}, \quad p_{4}\left(x_{4}\right)=\frac{1}{x_{4}^{2}+3 x_{4}+1}, \quad m=\frac{1}{6}
\end{gathered}
$$

Solution: $x^{*}=\{0.0386 ; 0.0848 ; 0.0251 ; 0.0927\}$. Global value: $f^{*}=-0.0206$.

Problem 4. Objective function:

$$
\begin{gathered}
f(x)=-(\langle A x, x\rangle-\langle b, x\rangle), \quad b=(1,2,3)^{t}, \\
\mathrm{~A}=\left(\begin{array}{lll}
1 & 2 & 3 \\
2 & 1 & 2 \\
3 & 2 & 1
\end{array}\right) .
\end{gathered}
$$

Constraint functions:

$$
p_{1}\left(x_{1}\right)=\frac{1}{x_{1}^{3}+2 x_{1}^{2}+3 x_{1}+4}, \quad p_{2}\left(x_{2}\right)=\frac{1}{x_{2}^{2}+4 x_{2}+3}, \quad p_{3}\left(x_{3}\right)=\frac{1}{x_{3}^{4}-x_{3}+1}, \quad m=1
$$

Solution: $x^{*}=\{0 ; 1.3668 ; 1.0672\}$. Global value: $f^{*}=9.2635$.

Problem 5. Objective function:

$$
f(x)=-(\langle A x, x\rangle-\langle b, x\rangle), \quad b=(3,4,2,1)^{t},
$$




$$
A=\left(\begin{array}{llll}
4 & 3 & 2 & 1 \\
3 & 4 & 3 & 2 \\
2 & 3 & 4 & 3 \\
1 & 2 & 3 & 4
\end{array}\right)
$$

Constraint functions:

$$
\begin{gathered}
p_{1}\left(x_{1}\right)=\frac{1}{x_{1}^{5}+2 x_{1}^{3}+x_{1}+2}, \quad p_{2}\left(x_{2}\right)=\frac{1}{x_{2}^{3}+2 x_{2}+2}, \\
p_{3}\left(x_{3}\right)=\frac{1}{x_{3}^{4}+x_{3}^{2}+x_{3}+1}, \quad p_{4}\left(x_{4}\right)=\frac{1}{x_{4}^{3}+2 x_{4}^{2}+x_{4}+1}, \quad m=\frac{1}{5}
\end{gathered}
$$

Solution: $x^{*}=\{0 ; 0 ; 0 ; 1\}$. Global value: $f^{*}=-3$.

Problem 6. Objective function:

$$
\begin{gathered}
f(x)=-(\langle A x, x\rangle-\langle b, x\rangle), \quad b=(1,2,3,4,5)^{t}, \\
A=\left(\begin{array}{rrrrr}
5 & 4 & 3 & 2 & 1 \\
4 & 5 & 4 & 3 & 2 \\
3 & 4 & 5 & 4 & 3 \\
2 & 3 & 4 & 5 & 4 \\
1 & 2 & 3 & 4 & 5
\end{array}\right) .
\end{gathered}
$$

Constraint functions:

$$
\begin{gathered}
p_{1}\left(x_{1}\right)=\frac{1}{x_{1}+1}, \quad p_{2}\left(x_{2}\right)=\frac{1}{x_{2}^{2}+2}, \quad p_{3}\left(x_{3}\right)=\frac{1}{x_{3}^{3}+3}, \\
p_{4}\left(x_{4}\right)=\frac{1}{x_{4}^{4}+4}, \quad p_{5}\left(x_{5}\right)=\frac{1}{x_{5}^{5}+5}, \quad m=\frac{1}{6} .
\end{gathered}
$$

Solution: $x^{*}=\{0.0718 ; 0 ; 0 ; 0.5016\}$. Global value: $f^{*}=1.2240$.

Problem 7. Objective function:

$$
\begin{gathered}
f(x)=-(\langle A x, x\rangle-\langle b, x\rangle), \quad b=(1,2,3,4,5,6)^{t}, \\
\mathrm{~A}=\left(\begin{array}{rrrrrr}
6 & 5 & 4 & 3 & 2 & 1 \\
5 & 6 & 5 & 4 & 3 & 2 \\
4 & 5 & 6 & 5 & 4 & 3 \\
3 & 4 & 5 & 6 & 5 & 4 \\
2 & 3 & 4 & 5 & 6 & 5 \\
1 & 2 & 3 & 4 & 5 & 6
\end{array}\right)
\end{gathered}
$$


Constraint functions:

$$
\begin{gathered}
p_{1}\left(x_{1}\right)=\frac{1}{x_{1}+1}, \quad p_{2}\left(x_{2}\right)=\frac{1}{x_{2}^{2}+2}, \quad p_{3}\left(x_{3}\right)=\frac{1}{x_{3}^{3}+3}, \quad p_{4}\left(x_{4}\right)=\frac{1}{x_{4}^{4}+4}, \\
p_{5}\left(x_{5}\right)=\frac{1}{x_{5}^{5}+5}, \quad p_{6}\left(x_{6}\right)=\frac{1}{x_{6}^{6}+6}, \quad m=\frac{1}{7}
\end{gathered}
$$

Solution: $x^{*}=\{0.063 ; 0 ; 0 ; 0 ; 0 ; 0.5012\}$. Global value: $f^{*}=1.4758$.

Problem 8. Objective function:

$$
\begin{gathered}
f(x)=-(\langle A x, x\rangle-\langle b, x\rangle), \quad b=(1,2,3, \ldots, n)^{t}, \\
\mathrm{~A}=\left(\begin{array}{ccccccc}
n & n-1 & n-2 & \ldots & 2 & 1 \\
1 & n & n-1 & \ldots & 3 & 2 \\
2 & 1 & n-1 & \ldots & 4 & 3 \\
\ldots & \ldots & \ldots & \ldots & \ldots & \ldots \\
2 & 3 & 4 & \ldots & n & n-1 \\
1 & 2 & 3 & \ldots & n-1 & n
\end{array}\right)
\end{gathered}
$$

Constraint functions:

$$
p_{i}\left(x_{i}\right)=\frac{i}{\left(x_{i}+i\right)^{i}}, \quad i=1,2, \cdots, n, \quad m=\frac{1}{n+1} .
$$

\begin{tabular}{|c|c|c|l|}
\hline & Local value & Global value & $\begin{array}{l}\text { Computing } \\
\text { time }\end{array}$ \\
\hline $\mathrm{n}=10$ & 3.0148 & 7.9959 & $120.809 \mathrm{~s}$ \\
\hline $\mathrm{n}=20$ & 1.759 & 8.1489 & $185.44 \mathrm{~s}$ \\
\hline $\mathrm{n}=30$ & 1.4538 & 12.8993 & $215.68 \mathrm{~s}$ \\
\hline $\mathrm{n}=40$ & 1.0596 & 17.7212 & $284.44 \mathrm{~s}$ \\
\hline $\mathrm{n}=50$ & 1.2019 & 24.7729 & $322.21 \mathrm{~s}$ \\
\hline $\mathrm{n}=100$ & 1.2043 & 83.4694 & $1542.85 \mathrm{~s}$ \\
\hline
\end{tabular}

Table 1: Numerical experiments 


\section{Conclusions}

In this article, for the first time, the utility maximization for oligopsonistic market has been considered. We derived global optimality conditions and proposed a method for solving the utility maximization problem. We provided theoretical results with numerical examples.

\section{References}

[1] Aubin,J.P., Optima and Equilibria:An Introduction to Nonlinear Analysis, Springer, 1998.

[2] Arrow,K.J. and Enthoven, A.C., Quasiconcave Programming., Econometrica $29,779-800,1961$.

[3] Bazaraa,M.S. and Shetty, C.M. Foundations of Optimization. SpringerVerlag, Berlin, 1976.

[4] Bertsekas,D.P., Nolinear Programming., 2nd edition, Athena Scientific, Belmont, MA,1999.

[5] David Romer., Advanced Macroeconomics, University of California, Berkeley 1996.

[6] Debreu,G., Least Concave Utility Functions., Journal of Mathematical Economics, 3(2), pp. 121-129, 1976

[7] Dixit, A.K., Optimization in Economic Theory., Oxford University Press, 1976

[8] Donald W.Kartzner, Walrasion Microeconomics., Addison-Welsey, NewYork,1988

[9] Enkhbat,R. and Ibaraki.T, On the Maximizaion and Minimization of a Quasiconvex Function., Journal of Nonlinear and Convex Analysis, Vo..4, No.1, pp. 43-76. 2003

[10] Gregory Mankiw.H., Macro Economics, Harvard University, Worth Publisher, 2000.

[11] James M.Henderson and Richard E.Quandt., Microeconomic Theory:A Mathematical Approach., McGraw-Hill.,1971 
[12] Katzner, D.W. Static Demand Theory. MacMillan, New York, N.Y.

[13] Michael D.Intriligator., Mathematical Optimization and Economic Theory, Prentice-Hall, 2002.

[14] Paul Madden.,Concavity and optimization in microeconomics, Oxford University Press, 1986.

[15] Varian,H.R., Microeconomics Analysis., Norton, New-York, 1984. 
